\title{
MONARQUÍA, ARTE Y PODER EN UNA DIÓCESIS FRONTERIZA: LA ANTIGUA DIÓCESIS DE TUI Y EL DESARROLLO DEL ARTE ROMÁNICO EN EL SUROESTE DE GALICIA Y EN EL NORTE DE Portugal
}

\section{MonarChy, ART AND POWER IN A FRONTIER DIOCESE: THE ANCIENT DIOCESE OF TUI AND THE DEVELOPMENT OF Romanesque ART IN SOUTHWESTERN GALICIA AND NORTHERN PORTUGAL}

\author{
Margarita Vázquez Corbal \\ Universidad de Santiago de Compostela
}

Recibido: 31/03/2017 Evaluado: 18/04/2017 Aprobado: 04/07/2017

Resumen: La antigua diócesis de Tui, debido a su estratégica posición a orillas del Miño, fue desde el siglo $\mathrm{v}$ hasta mediados del siglo xv un obispado transfronterizo que abarcaba territorios del suroeste de $\mathrm{Ga}$ licia y del norte de Portugal. Este territorio diocesano fue un espacio privilegiado para las luchas de poder entre monarcas y nobles de ambos lados de la frontera, que contribuyeron al nacimiento, el desarrollo y la expansión del arte románico en este territorio.

Palabras clave: monarquía, arte, poder, frontera, románico.

ABSTRACT: The ancient diocese of Tui was, due to its strategic location on the banks of the Miño river, a borderline bishopric which encompassed territories in southwestern Galicia and northern Portugal from the 5 th to the 15 th century. This diocesan space was a privileged space for 
power struggles between monarchs and nobility from both sides of the frontier which contributed to the birth, development and expansion of Romanesque art in this territory.

Keywords: Monarchy, art, power, frontier, Romanesque.

\section{LA ANTIGUA DIÓCESIS DE TUI, UN TERRITORIO MEDIEVAL TRANSFRONTERIZO}

$\mathrm{T}$ ude, o Tui, fue un importante aglomerado secundario romano que gozó de un papel preponderante como sede episcopal en la época tardoantigua y sueva. El Parrochiale suevorum o Divisio Theodomiri nos muestra ya su situación estratégica a finales del siglo vi, pues recoge las diferentes ecclesias y pagi a ambos lados del Miño. ${ }^{1}$ Contaba con 17 arciprestazgos que coincidían con la organización civil en terras que apenas registraron cambios durante el período medieval. ${ }^{2}$ Aunque, si debemos destacar un documento de gran utilidad para el conocimiento de ese carácter fronterizo, ese es el conocido como Igrejas do bispado de Tui, no território de entre Lima e Minho, conservado en el Arquivo Nacional do Torre do Tombo (Lisboa), donde se indica que 155 iglesias de esta región del norte de Portugal estaban bajo la jurisdicción del obispado de Tui. ${ }^{3}$ Esta condición transfronteriza se mantuvo hasta 1381, fecha en la que se produjo el llamado Cisma de Valença do Minho, por el que clérigos tudenses, junto al exiliado Juan García Manrique, se instalan en la Colegiata de Santo Estevão de Valença do Minho (Portugal) y se declaran bajo la jurisdicción del papa Urbano VII. ${ }^{4}$ Esta situación precipitó la disgregación de la parte portuguesa de la diócesis, que sería definitiva en 1444 con la anexión de Entre-Minho-e-Lima a Ceuta por medio de una bula de Eugenio IV.

Por lo tanto, estamos ante una diócesis donde el poder episcopal es único ya desde sus inicios y que supera las fronteras naturales, territoriales y políticas; al menos, hasta el último cuarto del siglo XIV. Este se encuentra por encima de las disputas políticas que rodean a su ámbito territorial, dividido primeramen-

1. José CARlos SÁnChez PARdo (2014): «Organización eclesiástica y social en la Galicia tardoantigua.

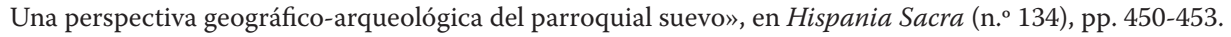

2. Para los arciprestazgos tudenses y su denominación en la Edad Media, véase Fernando López Alsina: «La cristalización de Tui como espacio del poder señorial entre 1095-1157», en MARTA CENDóN Fernández, Silvia González Soutelo (2006): Tui: Pasado, presente y futuro. Pontevedra: Diputación de Pontevedra, pp. 67-68. Y en MARTa Cendón FernándeZ «El arte medieval en Tui: la catedral como foco receptor y difusor del románico y del gótico», en MARTa Cendón Fernández, Silvia González Soutelo (2006): Tui: Pasado, presente y futuro. Pontevedra: Diputación de Pontevedra, pp. 131.

3. «Igrejas do bispado de Tui no território de entre Lima e Minho 1320», en Gaveta 19 (Maço 4, Documento 7, folios 5-7). Arquivo Nacional da Torre do Tombo.

4. Paz Romero Portilla (2006): «Un observatorio privilegiado de las relaciones entre Castilla y Portugal: Tuy en la Edad Media», en Estudos em Homenagem ao Professor Doutor José Marques, Facultade de Letras da Universidade do Porto, pp. 252-253. 
te entre los condados de Galicia y Portugal y, posteriormente, entre los reinos de León, Castilla y Portugal.

El PODER REAL, LA NOBLEZA Y SU RELACIÓN CON LA ANTIGUA DIÓCESIS DE TUI

La monarquía desempeñará un papel importantísimo en el desarrollo de la antigua diócesis de Tui, tanto a nivel histórico como artístico.

Tras un período especialmente convulso, comprendido entre los siglos viI y IX, la sede es restaurada en el 915 por Ordoño II, con Hermogio como obispo; pero, debido a las invasiones que sufre y a la destrucción de la sede, este huirá al Monasterio de Labrugia (Portugal). La situación se agravará especialmente a principios del siglo XI como consecuencia de las diversas incursiones vikingas, como la de Olaf del año 1008, ${ }^{5}$ lo que conllevará que Alfonso V decrete su anexión a Compostela en 1024.

Tradicionalmente se venía considerando que la restitución de la sede tudense se produciría entre 1070 y 1071, ya que no existía consenso entre diversos autores sobre si considerar el diploma de la infanta Urraca de $1071^{6} \mathrm{o}$ la donación del rey García al obispo Jorge de la villa de Vilar de Mouros (Caminha, Portugal) del mismo año ${ }^{7}$ como documentos acreditativos de la nueva restauración de la sede, si bien, este último documento nos indicaría que la sede ya estaba restaurada en dicho año. Sin embargo, la documentación portuguesa nos lleva a suponer que García fue quien la restauró hacia 1067-1068, porque ya consta el Obispo Jorge consagrando el Monasterio de São Salvador da Torre (Viana do Castelo, Portugal) en $1068 .{ }^{8}$ Cabe destacar que, pese a contar con una sede restaurada, el culto y otras funciones propias de la sede catedralicia se llevaban a cabo en el Monasterio de San Bartolomé de Rebordáns (Tui, Pontevedra), ${ }^{9}$ al menos hasta 1179 cuando el obispo Beltrán traslada su residencia y abandona dicho monasterio. ${ }^{10}$

El rol de la monarquía, como hemos visto, es muy importante desde el punto de vista de las refundaciones de la sede pero, sin duda, los papeles de la monarquía y la nobleza respecto al desarrollo y el enriquecimiento de la diócesis

5. «La cristalización de Tui como espacio del poder señorial entre 1095-1157», en MARTA CENDóN Fernández, Silvia González Soutelo (2006): Tui: Pasado, presente y futuro. Pontevedra: Diputación de Pontevedra, pp. 58-63.

6. Manuel Rubén García Álvarez (1962): «El diploma de restauración de la sede de Tui por la infanta Urraca», Cuadernos de Estudios Gallegos (tomo 17, n. ${ }^{\circ}$ 52), pp. 275-292.

7. José Miguel Andrade Cernadas (1997): «Fuentes documentales para el estudio del rey García de Galicia», en Minius (n. ${ }^{\circ}$ 6), pp. 47-49.

8. Rui de Azevedo (1958): Documentos Medievais Portugueses (vol. I). Lisboa: Academia Portuguesa da História, p. 261.

9. Marta Cendón Fernández (2000): La catedral de Tui en época medieval. Pontevedra: Fundación Cultural Rutas del Románico, p. 19.

10. Julio Martínez Sigüenza (2003): «As parroquias de Tui. Síntese Histórica», en Pontevedra. Revista de Estudos Provinciais (n. ${ }^{\circ}$ 19), p. 50. 
gozarán de mayor relevancia a partir de finales del siglo XI, y especialmente a partir de 1097, cuando Alfonso VI entrega como dote a sus hijas Urraca y Teresa y a sus respectivos maridos, Raimundo y Enrique de Borgoña, los condados de Galicia y Portugal. A este respecto son destacables dos documentos: en primer lugar, el privilegio de coto que en 1095 recibe la ciudad de Tui, en el cual se destacan tres aspectos: la mención a la advocación mariana de la sede catedralicia, la referencia a su obispo y canónigos, y la extensión del coto a ambos lados del Miño. ${ }^{11} \mathrm{Y}$, en segundo lugar, la donación del Monasterio de Ázere, que Enrique conde de Portugal y marido de Teresa hace a la Catedral de Tui en $1110 .{ }^{12} \mathrm{~A}$ través de estos documentos podemos apreciar que ambos condados establecen una lucha por la hegemonía del poder en la zona a través del uso de las donaciones; situación que seguirá a través de las realizadas por Urraca y Teresa en solitario. El año 1112 será una fecha clave, porque Urraca ya es reina y, ostentando tal condición, otorgará un diploma a la Catedral de Tui $^{13}$ que afecta al territorio de la margen derecha del Miño y transfiere todo el patrimonio que le corresponde a ella como infanta, condesa y reina: «lo que pertenece al derecho real con su caritel, voz y honor». ${ }^{14}$ Apenas cinco años después, Teresa de Portugal empieza a intitularse como regina en la documentación, y responde así a las expectativas de la nobleza portuguesa que deseaba la independencia. Sin embargo, el condado portugués es invadido, y Teresa debe someterse a su hermanastra Urraca. En 1125 se empieza a fraguar una revuelta de los nobles portugueses a la que dos años más tarde se unirá el infante Alfonso Enríquez, futuro rey de Portugal. ${ }^{15}$ En este mismo año, Teresa de Portugal realiza tres donaciones a la Catedral de Tui: dos con fecha del 2 de septiembre, ${ }^{16}$ y otra dos días después. ${ }^{17}$ En ambas no solo dona diferentes monasterios e iglesias de la región de Entre Minho-e-Lima a la Catedral de Tui, sino que también le otorga importantes privilegios. Finalmente, en 1128 realiza una tercera donación, en la que da la mitad del realengo de Fonte Arcada (Arcos de Valdevez). ${ }^{18}$ Estas donaciones representan una maniobra con afán de reafirmar su posición en el territorio.

11. Manuel Recuero Astray, M.a Ángeles garcía Prieto, Paz Romero Portilla (2002): Documentos medievales del Reino de Galicia: doña Urraca (1095-1126). La Coruña: Xunta de Galicia, pp. 33-35

12. Rui de Azevedo (1958): Documentos Medievais Portugueses (vol. I). Lisboa: Academia Portuguesa da História, pp. 503-504.

13. Manuel Recuero Astray, M. a Ángeles garcía Prieto, Paz Romero Portilla (2002): Documentos medievales del Reino de Galicia: doña Urraca (1095-1126). La Coruña: Xunta de Galicia (doc. 60).

14. Fernando López Alsina: «La cristalización de Tui como espacio del poder señorial entre 10951157», en Marta Cendón Fernández, Silvia González Soutelo (2006): Tui: Pasado, presente y futuro. Pontevedra: Diputación de Pontevedra, p. 83.

15. Paz Romero Portilla (2004): «Valor de la documentación real portuguesa para la historia de Galicia en la Edad Media», en Cuadernos de Estudios Gallegos (tomo LI, fasc. 117), p. 222.

16. Enrique Flórez (1767): España Sagrada (tomo XXII). Madrid, pp. 256-259.

17. Rui de Azevedo (1958): Documentos Medievais Portugueses (vol. I). Lisboa: Academia Portuguesa da História, pp. 88-89.

18. Rui de Azevedo (1958): Documentos Medievais Portugueses (vol. I). Lisboa: Academia Portuguesa da História, pp. 517. 
Los herederos de Urraca y Teresa proseguirán con esta política de donaciones sistemáticas al obispo y la sede tudense intentando poner al prelado y la canónica tudense de parte de sus respectivas causas. Afonso Henriques da un paso firme en 1137 cuando intenta apropiarse de Toroño ${ }^{19} \mathrm{y}$ de la zona del Lima. Así pues, en compensación realiza donaciones a la sede tudense, que está bajo el mandato del obispo Pelayo Meléndez..$^{20}$ Paralelamente se firma el tratado de Tui, ${ }^{21}$ que pone fin a las hostilidades entre el infante portugués y su primo Alfonso VII. El monarca confirma en 1138 la reorganización del cabildo bajo la regla de San Agustín promulgada por el obispo Pelayo Meléndez. ${ }^{22}$ Tal vez debamos entender este hecho como otra maniobra de carácter político, esta vez por parte del hijo de Urraca para favorecer y buscar el apoyo del prelado tudense en detrimento del infante portugués, dado que este último es el principal defensor e impulsor de la orden de los canónigos regulares de San Agustín en Portugal. ${ }^{23}$ En 1142, el mismo monarca confirma las donaciones de sus antecesores a través de un privilegio que nos ofrece además un dato importante a nivel histórico-artístico que es la aprobación de la construcción de una torre defensiva junto al campanario de la catedral. ${ }^{24}$ Además de contribuir al impulso de la sede, Alfonso VII tendrá un destacado interés en el desarrollo de la cultura monástica en la diócesis a través de sus donaciones y confirmaciones al Monasterio de Santa María de Oia (1137) ${ }^{25}$, al de San Salvador de Barrantes, en Tomiño (1138), ${ }^{26}$ y al de Santa Eulalia de Donas en Gondomar (1149), ${ }^{27}$ situados en la provincia de Pontevedra.

Tras un período de relativa paz, Afonso Henriques, ya intitulado rey, vuelve a emprender una ofensiva en el territorio gallego del obispado y llega a tomar la propia capital episcopal en $1159,{ }^{28}$ donde firma en 1160 el acuerdo para unir a su hija Mafalda en matrimonio con el heredero de Aragón. ${ }^{29}$ Afonso Henri-

19. Sudoeste de la provincia de Pontevedra y zona que se corresponde con el ámbito gallego de la antigua diócesis de Tui. Sobre este tema véase: Manuel Fernández Rodríguez (2004): Toronium. Aproximación a la historia de una tierra medieval. Santiago de Compostela: Instituto Padre Sarmiento de Estudios Gallegos-CSIC.

20. Pascual Galindo Romeo (1923): Tuy en la Baja Edad Media, siglos XII-XV. Madrid CSIC, pp. VIII-IX.

21. José Antonio Fernández Flórez (1991): Colección Diplomática del Monasterio de Sahagún 857-1300. León, p. 161.

22. José Antonio Fernández Flórez (1991): Colección Diplomática del Monasterio de Sahagún 857-1300. León, pp. 260-261.

23. Nicolau de Santa María (1668): Chronica da Ordem dos Cônegos Regrantes do Patriarcha S. Agostinho. Lisboa, p. 123.

24. EnriQue Flórez (1767): España Sagrada (tomo XXII). Madrid, p. 267.

25. ENRIQUe Flórez (1767): España Sagrada (tomo XXII). Madrid, pp. 264-265.

26. Enrique Flórez (1767): España Sagrada (tomo XXII). Madrid, pp. 261-262.

27. Manuel Recuero Astray, Marta González Vázquez, Paz Romero Portilla (1998): Documentos medievales del Reino de Galicia: Alfonso VII (1116-1157). Santiago de Compostela: Xunta de Galicia, pp. 178-179.

28. Sobre las incursiones de Alfonso Enríquez véase: Amélia Aguiar Andrade (2001): «Afonso Henriques e a fronteira noroeste: contornos de uma estratégia», en A construção medieval do território. Lisboa: Livros Horizonte, pp. 77-79.

29. José BARBosa (1727): Catálogo cronológico, histórico, genealógico e crítico das rainhas de Portugal e seus filhos. Lisboa, p. 119. 
ques realizará donaciones a la sede tudense en $1169,{ }^{30}$ once años antes de ser proclamado rey por medio de la bula Manifestis Probatum ${ }^{31}$.

En 1170, Fernando II cambia el emplazamiento de la ciudad a un lugar más seguro y la dota de fueros. ${ }^{32}$ En 1179 le otorga permiso al obispo Beltrán para la construcción de un alcázar junto al palacio episcopal y cede también los importes de la venta de granos que, además de sufragar los gastos de construcción de la dicha estructura defensiva, son invertidos en otras labores constructivas de la sede catedralicia. ${ }^{33}$

La última gran donación real portuguesa a la Catedral de Tui durante el siglo XII vendrá de manos de Sancho I, que confirma la concesión de una iglesia y de varias ermitas. ${ }^{34}$ No obstante, en los siglos posteriores, las relaciones entre la monarquía portuguesa y la sede tudense continúan, e incluso se llega a la intervención de monarcas portugueses en asuntos y nombramientos puramente eclesiásticos..$^{35}$

El papel de la nobleza no será menos importante a la hora de articular y favorecer el desarrollo de este territorio. La despoblación de la zona fronteriza entre Portugal y León le dio a los nobles de ambos reinos la oportunidad de hacerse cargo de grandes espacios de terreno, pero también la de vender sus lealtades a Portugal o a León según sus propios intereses. ${ }^{36}$ Hemos de destacar que pocos ejemplos conservamos de donaciones directas a la sede y que son pocos los casos de fundaciones monásticas o eclesiásticas privadas, sobre todo en el caso de la zona gallega de la diócesis. Sin embargo, conservamos un ejemplo de noble transfronterizo paradigmático: el conde Gómez Núñez, teniente de Toroño entre 1116 y $1141,{ }^{37}$ junto a su hermano, dona a Cluny el Monasterio de San Salvador de Budiño en $1126 .{ }^{38}$ Se trata del mismo noble que en 1138 ostentaba temporalmente el Monasterio de San Salvador Barrantes. ${ }^{39}$ También cabe destacar la presencia de nobles con un importante rol militar y de servicio a la realeza, como Pedro Pélaez, alférez de Fernando II que junto a

30. «Donación de Afonso Henriques a la catedral de Tui del 28 de marzo de 1169», en Libro quarto de Privilegios Reales (perg. 4). Tui: Archivo de la Catedral de Tui.

31. «Bula Manifestis Probatum del 23 de Mayo de 1179». Bulas. Maço 16 (doc. 20). Lisboa: Arquivo Nacional de Torre do Tombo.

32. Ermelindo Portela Silva (1976): La región del obispado de Tui en los siglos XI-XV. Una sociedad en la expansión y en la crisis. Santiago de Compostela: Centro de Estudios Xacobeos - CSIC, p. 200.

33. Pascual Galindo Romeo (1923): Tuy en la Baja Edad Media, siglos XII-XV. Madrid: CSIC, p. XVII.

34. Rui de Azevedo (1979): Documentos de D. Sancho I (1174-1211). Coimbra, pp. 15-16.

35. Especialmente, durante el gobierno del monarca Pedro I, Paz Romero Portilla: «Un Observatorio privilegiado de las relaciones entre Castilla y Portugal: Tuy en la Edad Media», p. 250.

36. José Mattoso (1995): Identificação de um país. Ensaio sobre as origens de Portugal (1096-1325), Vol. I, Estampa, Lisboa, pp. 139-140.

37. Julio Ignacio González Montañes (2011): O Mosteiro de San Salvador de Budiño e a terra de Toroño, Instituto de Estudios Vigueses. Vigo, pp. 80-81.

38. Bernard Bruel (1876-1903): Récueil des chartes de l'abbaye de Cluny, V, París: Imprimerie Nationale, pp. 345-346.

39. Enrique Flórez (1767): España Sagrada (tomo XXII). Madrid, pp. 261-262. 
su mujer, Elvira Venegas, donan al obispo tudense la iglesia de Burgo Novo de Miñor. ${ }^{40}$

En el caso de Portugal, la nobleza tiene un papel más preponderante y reafirma su poder no solo a través de donaciones o fundaciones, como la de São Salvador de Bravães (Ponte da Barca, Portugal), ${ }^{41}$ sino también a través de la construcción de torres defensivas en relación con el concepto de ecclesia mea propia, y se hacen cargo de las labores de defensa y protección sufragando estas construcciones. ${ }^{42}$ En relación con esta idea debemos destacar las torres presentes en el Monasterio de São Martinho de Crasto (Ponte da Barca, Portugal), fundado por Ourigo Sueiro, ${ }^{43}$ y en Santa María de Vila Nova de Muía (Ponte da Barca, Portugal), fundación monástica de Godinho Fajes de Lanhoso ${ }^{44}$.

\section{LA SEDE CATEDRALICIA DE TUI, FOCO RECEPTOR Y DIFUSOR DEL ROMÁNICO EN LA ANTIGUA DIÓCESIS DE TUI}

Como hemos visto anteriormente, la sede catedralicia tudense disfrutó de numerosas prerrogativas para su enriquecimiento y su construcción; no obstante, sigue siendo un edificio de complejo estudio debido a dos factores: el desconocimiento de la fecha exacta de inicio de las obras y las dificultades para discernir el verdadero aspecto de su planta románica ${ }^{45}$ Respecto al primer aspecto podemos indicar que no existe consenso sobre este tema ${ }^{46}$, si bien un análisis pormenorizado de la documentación real que hemos mencionado anteriormente nos llevaría a determinar la siguiente cronología: el inicio de las obras se situaría en torno a 1122, cuando recibe la donación de la reina Urraca. Entre 1142 y 1145, las obras proseguirían a buen ritmo, ya que estaba construido un campanario y se recibe un impulso económico importante a través de

40. Margarita Vázquez Corbal (2015): El arte románico en la antigua diócesis de Tui, tesis doctoral. Compostela: Universidad de Santiago de Compostela, p. 329. Santiago.

41. Se considera tradicionalmente fundado por Vasco Nunes de Bravães, aunque existen dudas al respecto. Carlos Alberto Ferreira de Almeida: «A igreja românica de Bravães», en Avelino Jesús DA Costa (1998): Subsidios para a história da Terra de Nóbrega e do Concelho de Ponte da Barca (vol. I). Ponte da Barca, pp. 13-14.

42. Jorge Rodrigues (2001): «A imagem do poder no românico português», en Marisa CostA: Propaganda e Poder. Congresso Peninsular de História da Arte. Lisboa: Colibrí, p. 53.

43. Noble portugués de la frontera que dona en 1142 todos sus bienes para la fundación del monasterio. Nicolau de Santa María (1668): Chronica da Ordem dos Cônegos Regrantes do Patriarcha S. Agostinho. Lisboa (livro VI), p. 315.

44. Margarita Vázquez Corbal (2008): «La iglesia y el antiguo monasterio de Vila Nova de Muía (Ponte da Barca, Portugal)», en XXVI Ruta Cicloturística del Románico Internacional, pp. 213-215.

45. Sobre las diferentes hipótesis sobre su planta véase MARTA CENDÓN FERnÁNDEZ (1993): «Hipótesis sobre la planta medieval de la Catedral de Tui», Museo de Pontevedra (n. ${ }^{\circ}$ 47), pp. 101-122. Y CARMEN Manso Porto (2012): «Reflexiones sobre la catedral románica y gótica de Santa María de Tui», en Abrente (n. $\left.{ }^{\circ} 44\right)$, pp. 90-92.

46. Marta Cendón Fernández (2000): La catedral de Tui en época medieval. Pontevedra: Fundación Cultural Rutas del Románico, p. 22-24. Y, más específicamente sobre su construcción, en MARTA CENDóN Fernández (1994): «Las etapas constructivas de la catedral medieval de Tuy», en Tui: Museo e Arquivo Histórico Diocesano (vol. VII), pp. 197-212. 
una donación del Monasterio de Santa María de Oia. ${ }^{47}$ Gran parte de la obra románica estaría terminada en 1179 , aunque proseguían los trabajos cuando Fernando II cedió los importes de granos para la construcción de una torre y para obras de la catedral.

El análisis estilístico de los elementos arquitectónicos y escultóricos conservados en la sede catedralicia situados en la portada norte (fig. 1), exterior de la nave norte (fig. 2), crucero (figs. 3, 4, 5 y 6) y sala capitular románica (fig. 7) corroborarían estas fechas. Aunque los capiteles del crucero podrían datarse en la segunda mitad del XII ${ }^{48}$ el apuntamiento de ciertos tramos de la nave denota la transición al gótico. En el último tramo de la nave (fig. 8), más cercano a la fachada occidental, nos encontramos con formas puramente góticas coetáneas a su consagración, en 1225, y en relación con su fachada occidental, ya gótica del siglo XIII (fig. 9). A continuación se muestran las imagenes de la Catedral de Santa María de Tui en Pontenvedra:

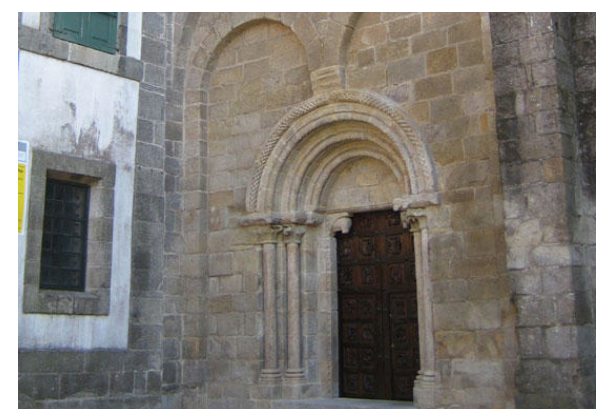

Fig. 1. Portada norte

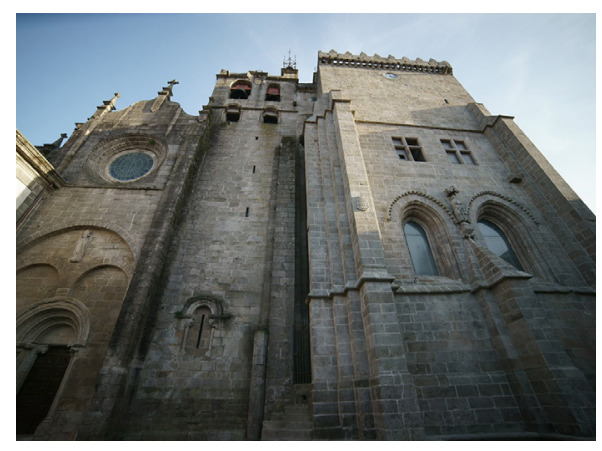

Fig. 2. Fachada norte

47. Enrique Flórez (1767): España Sagrada (tomo XXII). Madrid p. 269.

48. Sobre los capiteles véase Ernesto Iglesias Almeida (2014): «Los capiteles románicos de la Catedral de Tui», en XXXII Ruta del Románico Internacional. Pontevedra, pp. 122-124. 


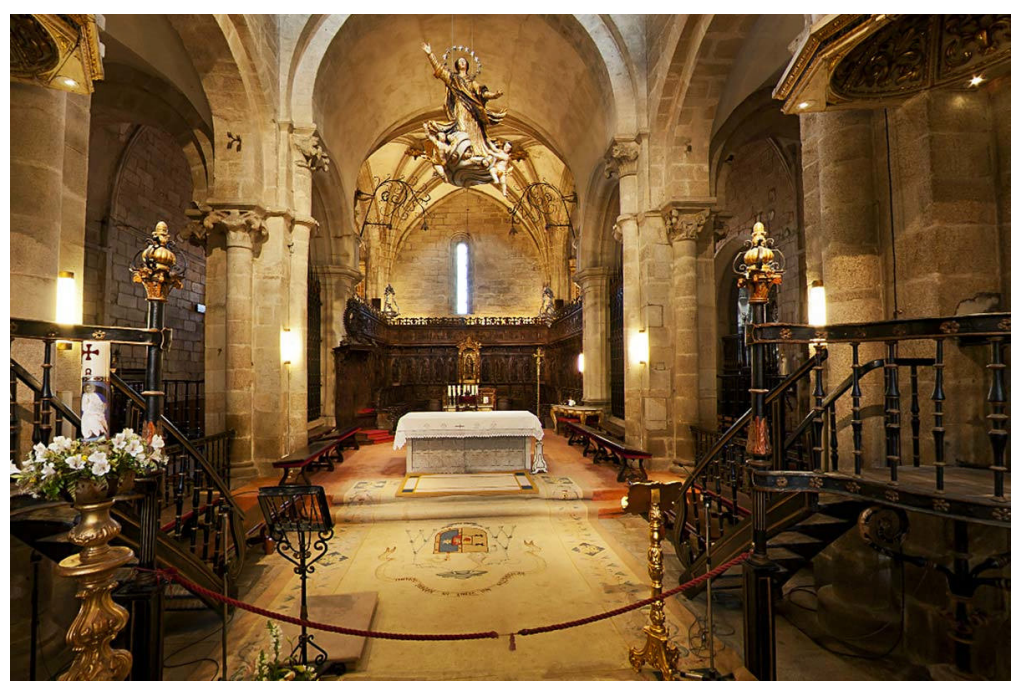

Fig. 3. Vista general del crucero y la capilla mayor

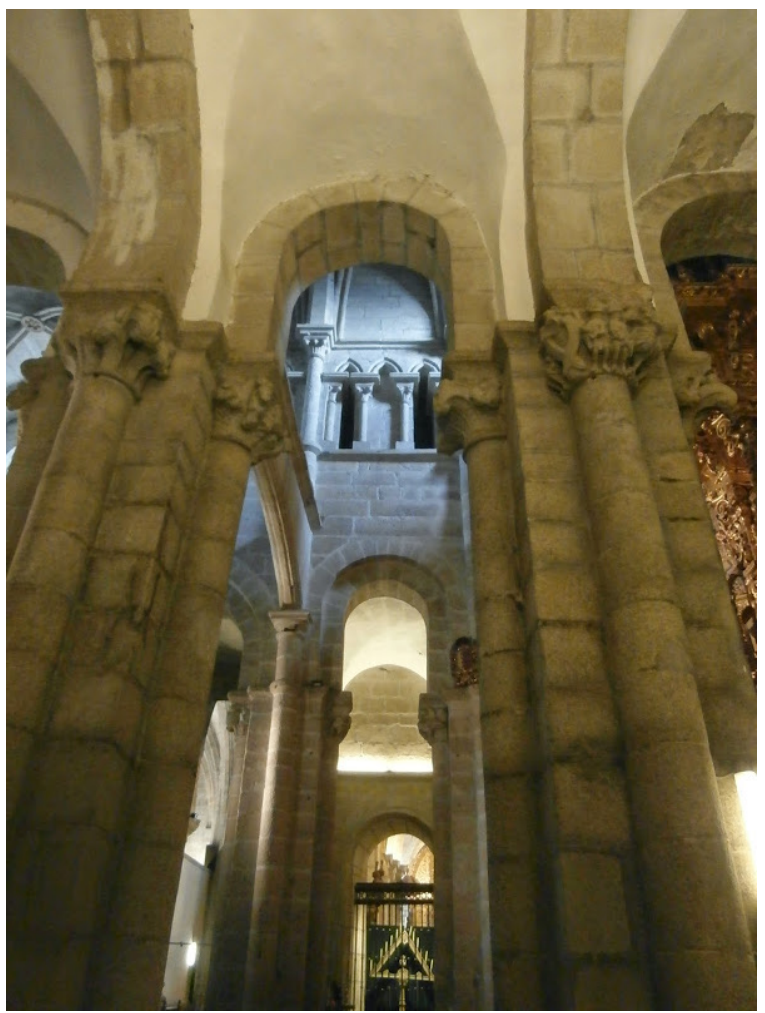

Fig. 4. Detalle del lado sur del crucero 


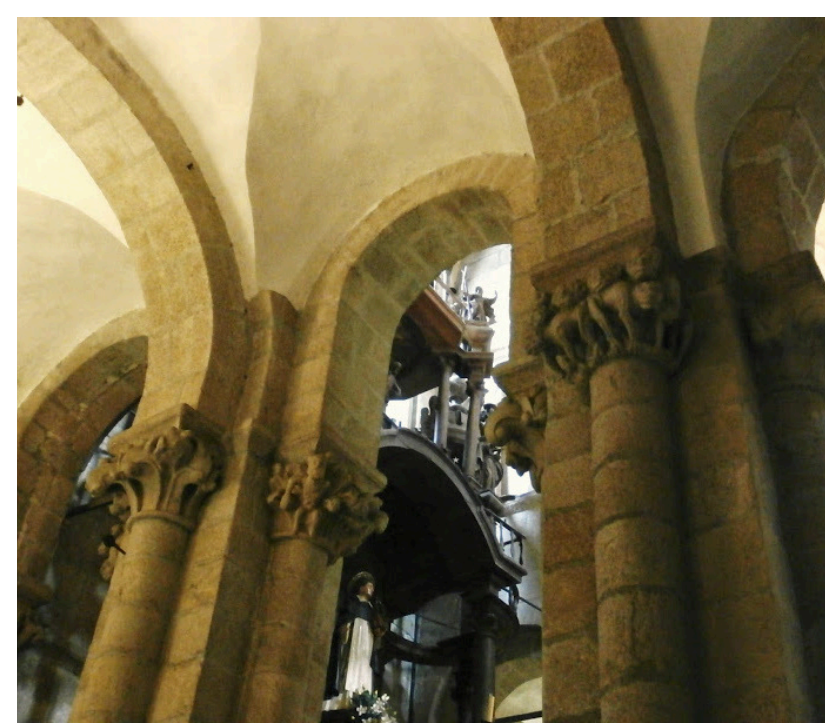

Fig. 5. Detalle del crucero

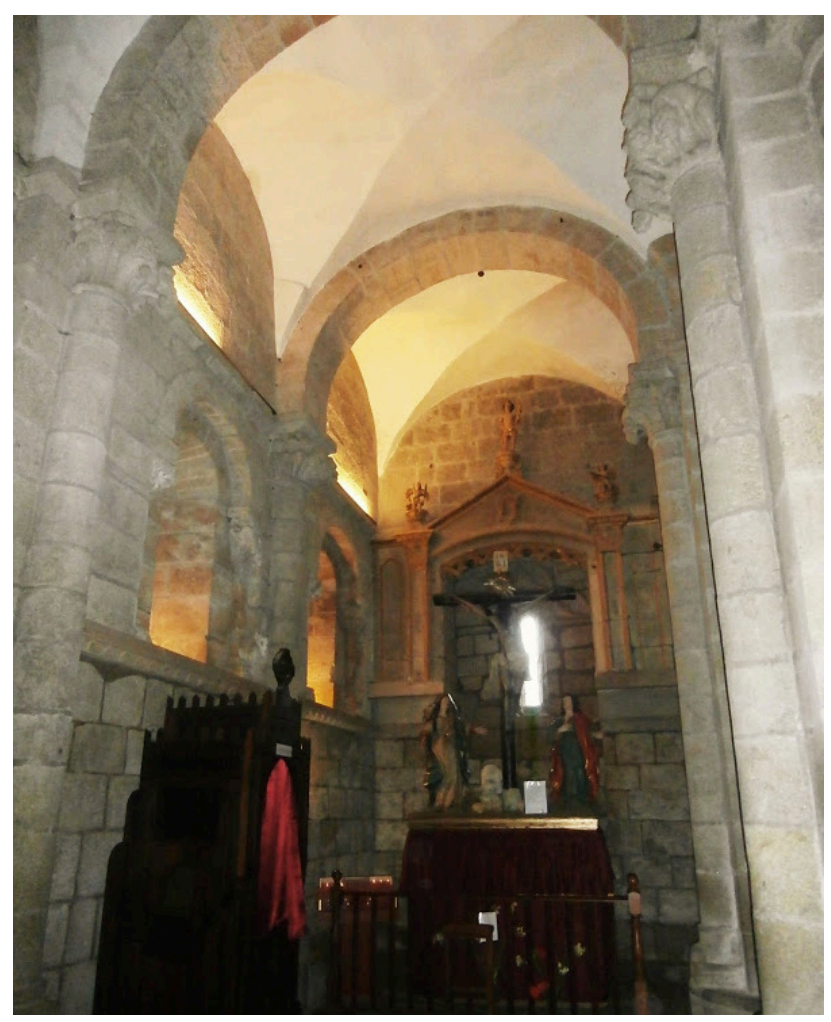

Fig. 6. Detalle de capilla del Cristo de la Agonía en la parte norte del crucero 


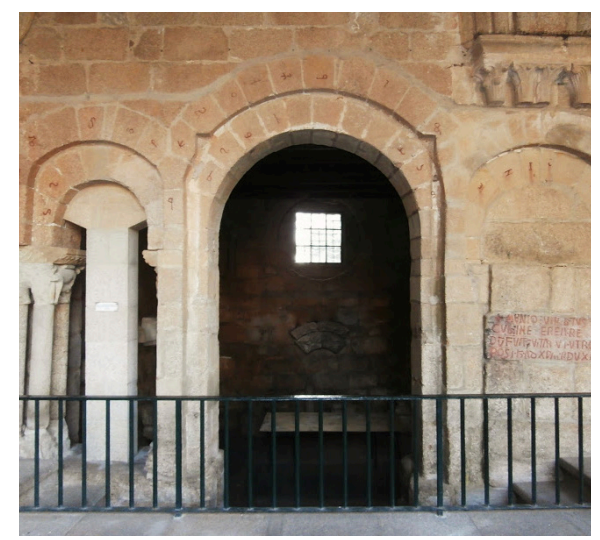

Fig. 7. Sala capitular románica

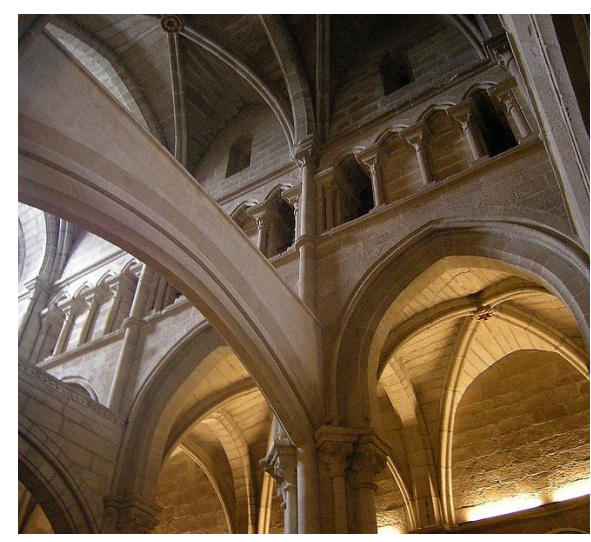

Fig. 8. Triforio y nave en la parte más cercana a la fachada occidental

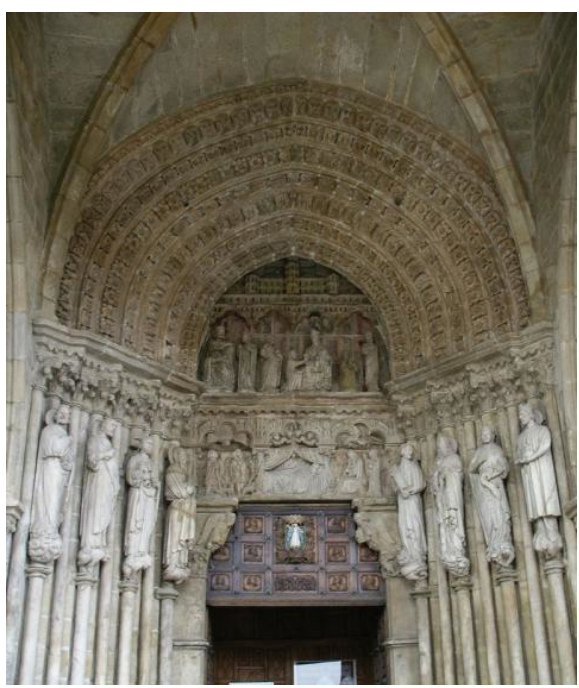

Fig. 9. Portada occidental 
La catedral de Tui es el foco receptor del románico, ya que recoge las premisas del románico a través de Santiago de Compostela. Recordemos además que Tui es el punto de entrada en territorio español de la principal vía de peregrinación portuguesa a Santiago de Compostela ${ }^{49}$ También es el foco difusor del mismo estilo, ya que tanto el modelo de su portada septentrional - con doble arquivolta, mochetas zoomórficas y jambas decoradas con un friso de pequeñas bolas- así como los modelos iconográficos y el tratamiento escultórico de los capiteles serán muy repetidos en el ámbito diocesano tudense, y fuera de este en regiones diocesanas limítrofes, como Braga. ${ }^{50}$

Además de lo expuesto hemos de destacar una característica de la catedral tudense: su aspecto fortificado. Aunque actualmente los elementos de fortificación conservados corresponden a etapas posteriores, la documentación escrita certifica que la catedral poseía, al menos, dos torres defensivas cuya construcción fue ordenada por Alfonso VII y Fernando II, respectivamente, y que fue necesaria su construcción por razones claramente estratégicas. Ambas torres fueron construidas hacia 1142 y 1179 , lo que coincide con períodos de alta conflictividad fronteriza por las repetidas incursiones de Afonso Henriques en la zona, entre 1126 y 1169. Aparte de la documentación conservamos un testimonio gráfico importante: el dibujo que Duarte Darmas recoge en su Livro das Fortalezas (1509-1510) de las ciudades de Tui y Valença do Minho donde todavía podemos advertir la presencia de las torres medievales (fig. 10).

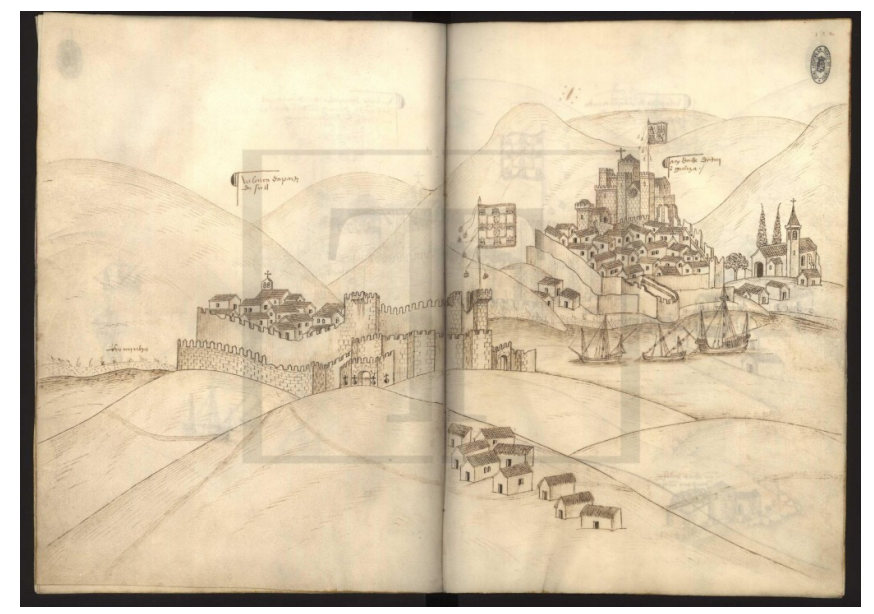

Fig. 10. Ciudades de Tui y Valença, en Livro das Fortalezas de Duarte d'Armas, 1509-1510 (Lisboa: ANTT, códices e manuscritos, 159, códice B, p. 112).

49. Humberto Baquero Moreno (1986): «Vías portuguesas de peregrinação a Santiago de Compostela na Idade Média», en Revista da Facultade de Letras da Universidade de Porto, História (n. $\left.{ }^{\circ} 3\right)$, pp. 77-90.

50. Para un análisis pormenorizado de estos modelos y de cómo y dónde se adoptan véase MARGARITA Vázquez Corbal (2015): El arte románico en la antigua diócesis de Tui, tesis doctoral. Santiago de Compostela: Universidade de Santiago de Compostela. 


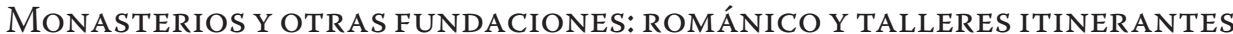

El arte románico en la antigua diócesis de Tui, además de la impronta dejada por el edificio catedralicio, se extenderá a través de diversas fundaciones monásticas y de las iglesias de patronazgo real o nobiliario. Sin duda, estas características influyen en la calidad de las obras por razones meramente económicas, que permitían tanto la contratación de talleres foráneos y diocesanos de gran calidad. En relación con esta idea debemos destacar tres fundaciones monásticas en el área gallega de la diócesis debidas a Alfonso VII ubicadas en Pontevedra: San Salvador de Barrantes, en Tomiño (figs. 11 y 12), Santa Eulalia de Donas, en Gondomar (figs. 13 y 14), y Santa María de Tomiño (figs. 15 y 16). Se trata de iglesias de monasterios benedictinos coetáneos, ya que sus fundaciones son del segundo cuarto del siglo XII y presentan rasgos estilísticos comunes; especialmente, en la estructura arquitectónica de sus capillas mayores y en la iconografía y la técnica escultórica de sus capiteles y canecillos. Esos aspectos podrían confirmar la existencia de un taller itinerante que, formado o proveniente de la propia catedral de Tui, desarrolla su actividad en los monasterios benedictinos de la zona y extiende su savoir-faire hasta la misma frontera con Braga en los monasterios portugueses de São Pedro de Rubiães, Paredes de Coura, y São Salvador de Bravães, Ponte da Barca ${ }^{51}$ (figs. 17 y 18), como podemos apreciar en las estatuas columna de sus portadas occidentales.
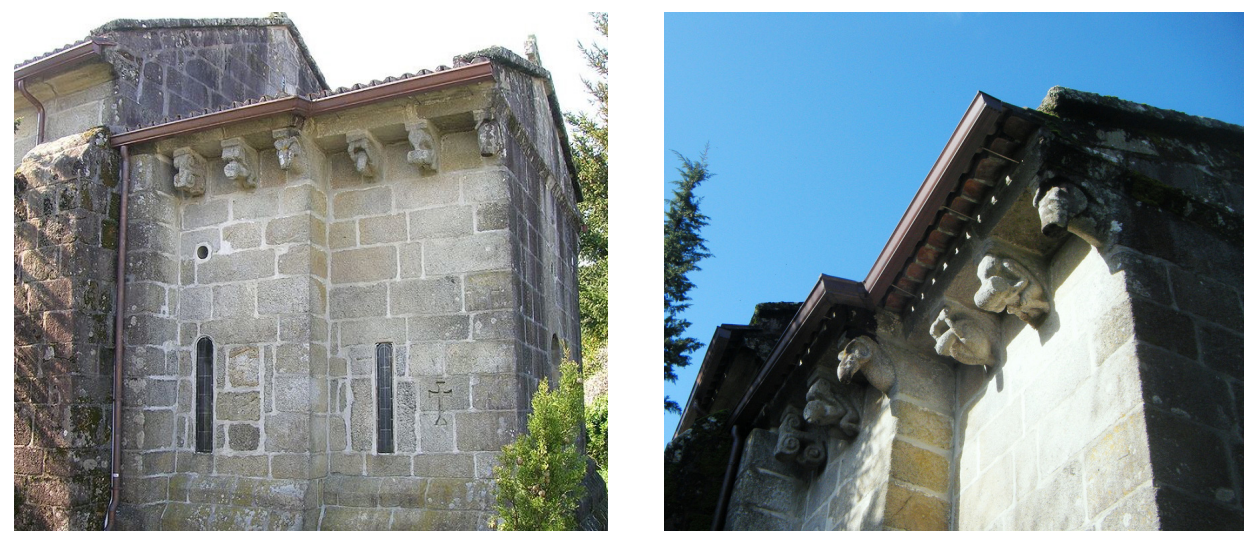

Figs. 11 y 12. Detalle del ábside y los canecillos en San Salvador de Barrantes (Tomiño, Pontevedra)

51. Véase sobre las relaciones entre Donas, Tomiño y los monasterios portugueses en MARGARITA VÁzQuez Corbal (2003): «La iglesia de Santa Eulalia de Donas: un ejemplo de las relaciones artísticas entre el Baixo Miño español y portugués», XXIV, Ruta Cicloturística del Románico Internacional (pp. 150-155). 


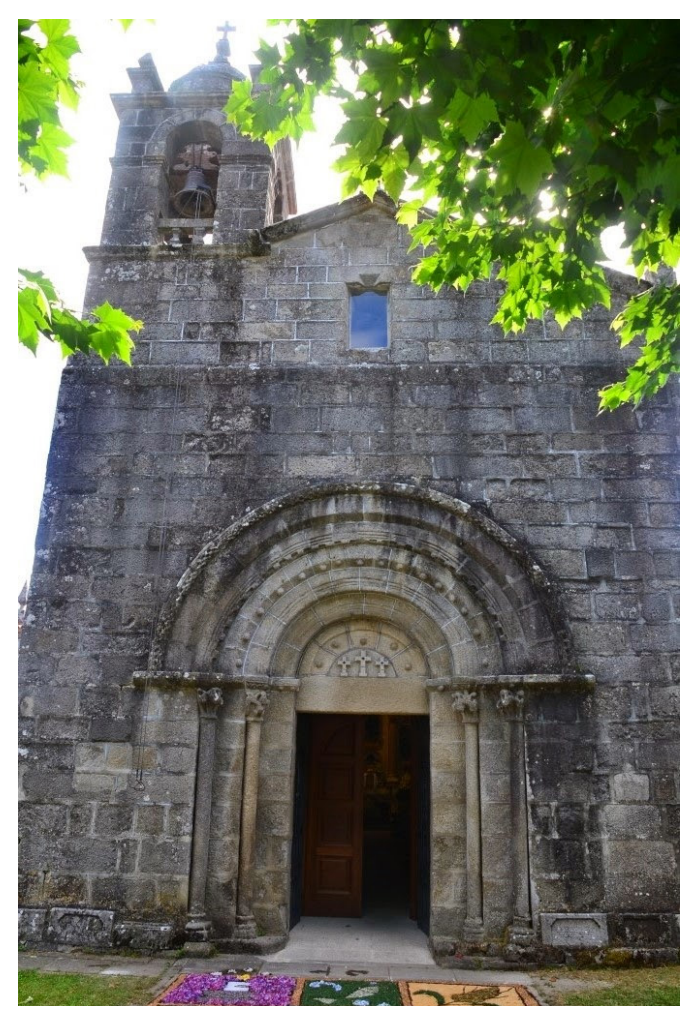

Fig. 13. Portada occidental de la Iglesia de Santa Eulalia de Donas

(Gondomar, Pontevedra)

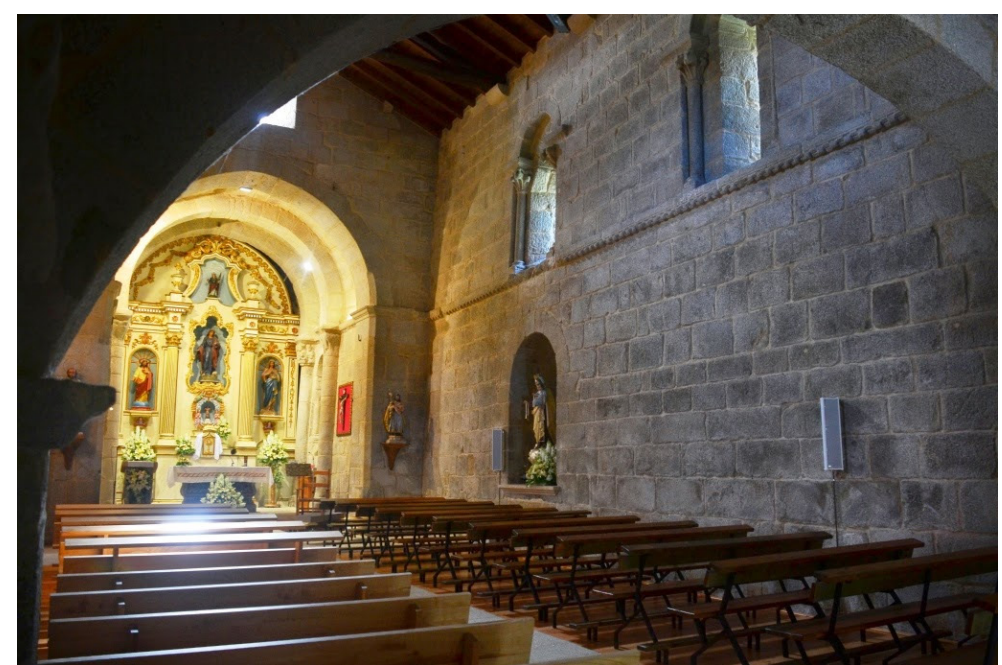

Fig. 14. Interior y ábside de la Iglesia de Santa Eulalia de Donas (Gondomar, Pontevedra) 


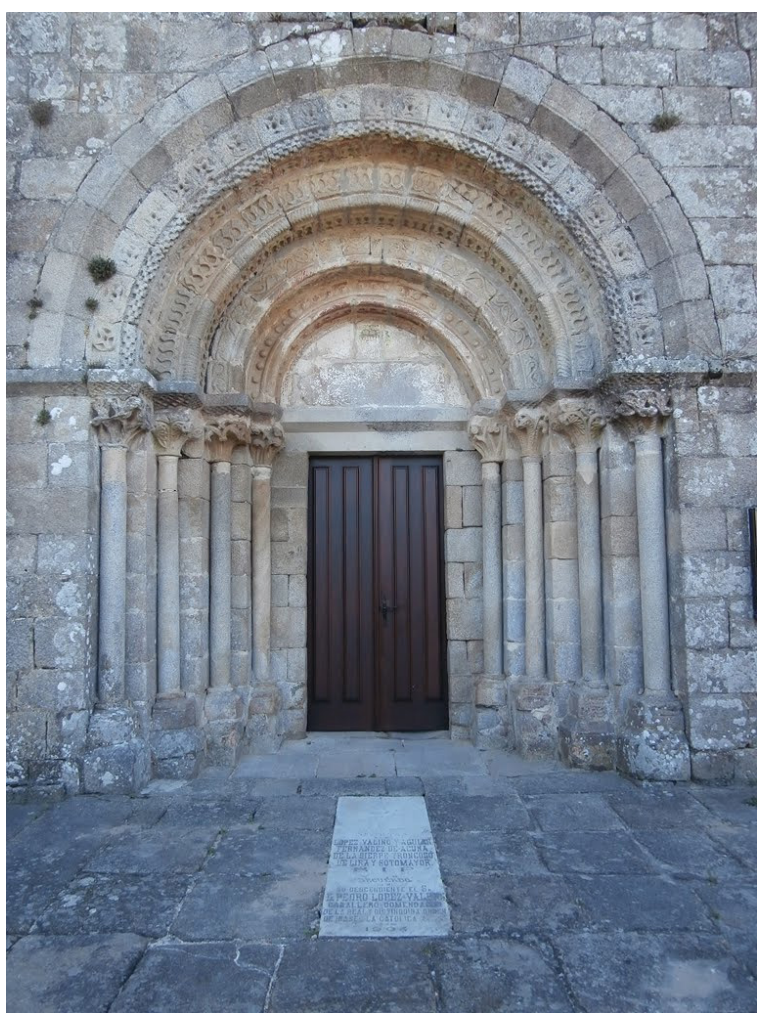

Fig. 15. Portada occidental de la Iglesia de Santa María (Tomiño, Pontevedra)

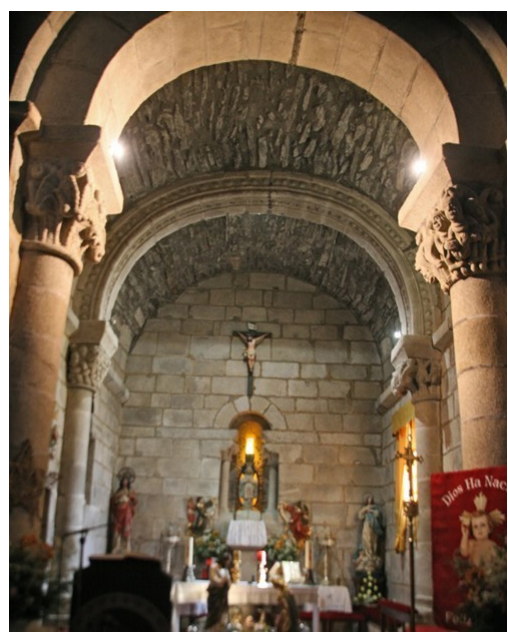

Fig. 16. Vista del ábside de la iglesia de Santa María (Tomiño, Pontevedra) 


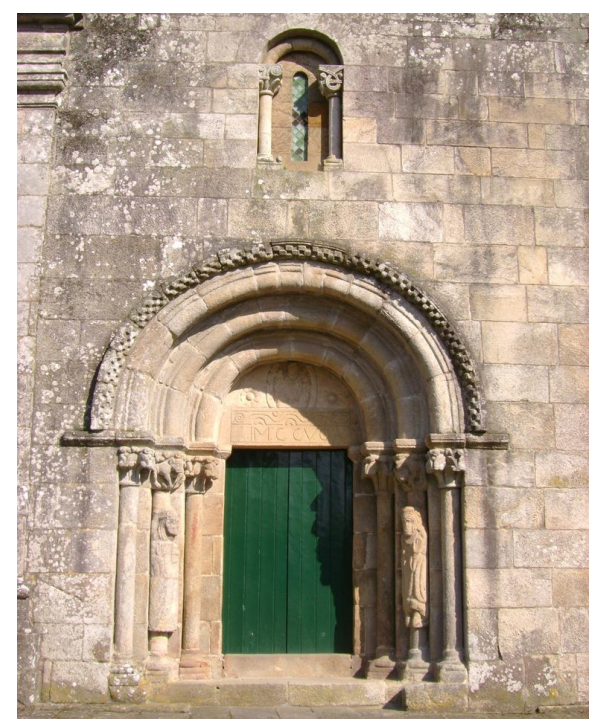

Fig. 17. Portada occidental de la Iglesia de São Pedro de Rubiães (Paredes de Coura, Portugal)

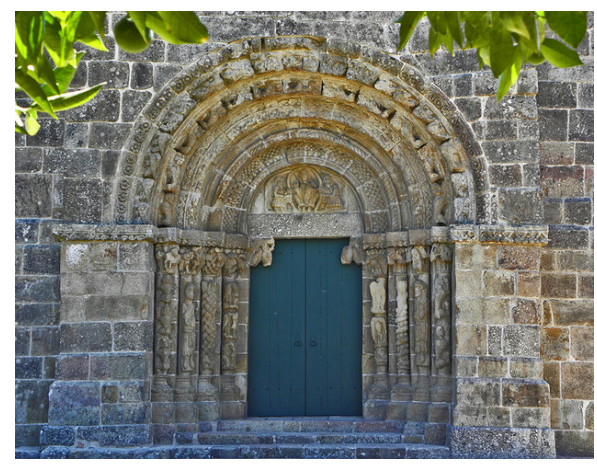

Fig. 18. Portada occidental de la Iglesia de São Salvador de Bravães (Ponte da Barca, Portugal)

En el área portuguesa de la diócesis destacamos una primitiva fundación monástica de doña Teresa de Portugal, posteriormente dotada y acotada por Afonso Enriques, como elemento de innovación en el románico de esta zona. Se trata de Santa María de Ermelo (Arcos de Valdevez, Portugal), cuya cabecera actual (fig. 19) corresponde a un primer período constructivo donde la idea de una planta de triple cabecera fue drásticamente modificada bien por razones económicas o por su anexión al Císter en el siglo XIII. Además, presenta un 


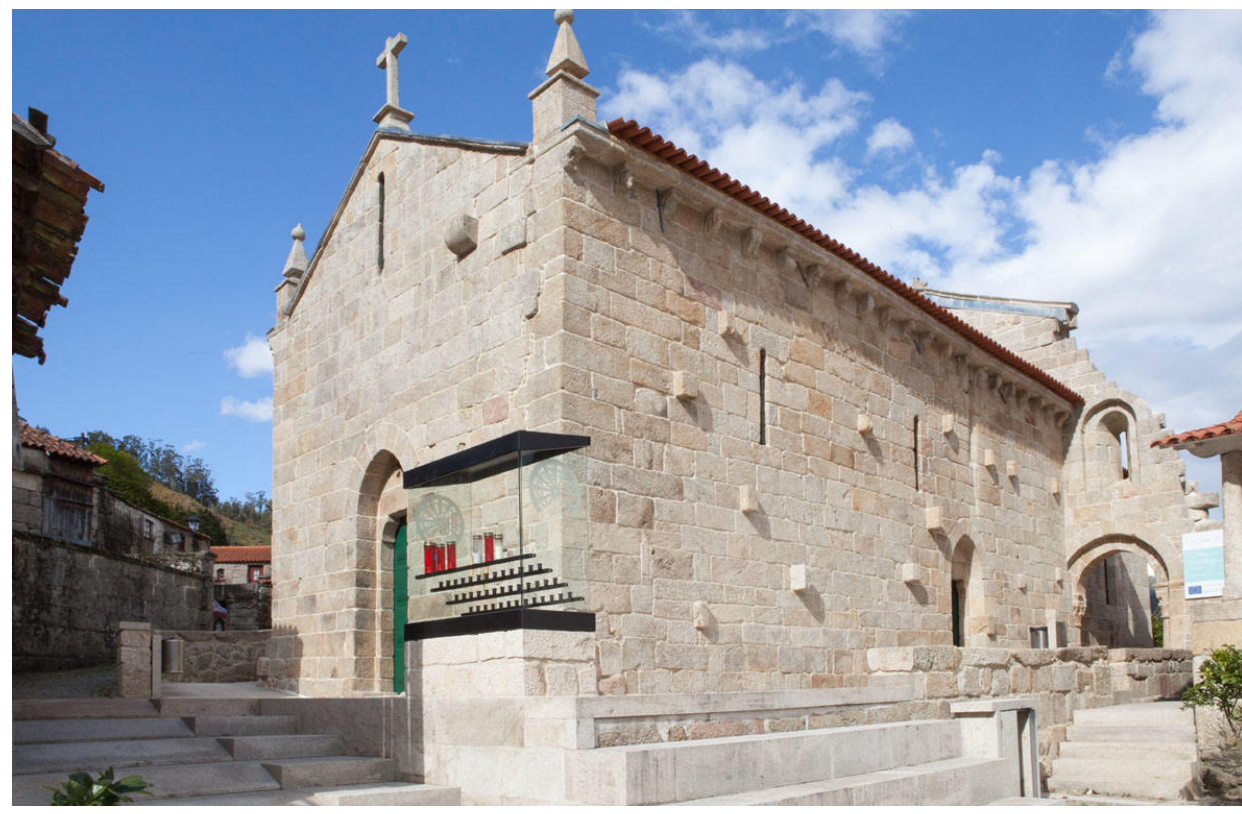

Fig. 19. Detalle de la nave y de la parte de la modificación de la cabecera románica del Monasterio de Santa María de Ermelo (Arcos de Valdevez, Portugal)

aspecto muy diferente debido a las reformas barrocas de las que fue objeto. ${ }^{52}$ Este ejemplo pone de manifiesto que en la vertiente portuguesa de la diócesis de Tui tenemos dos grandes tendencias estilísticas: una, influenciada por Tui y los ejemplos gallegos que se concentran en las localidades portuguesas más cercanas a la sede episcopal y al río Miño; la otra, concentrada en los ejemplos más cercanos a la frontera con Braga y al río Limia, cuyos paralelos se encuentran más en relación con Braga y con el arte del Císter ${ }^{53}$.

Un análisis de las fuentes documentales y de los elementos estilísticos nos puede llevar a afirmar que, en las iglesias y los monasterios de la antigua diócesis de Tui, el románico se utiliza como un medio de reafirmación de la identidad, especialmente en la zona portuguesa. En dicho ámbito es más frecuente que los monasterios e iglesias directamente fundados o beneficiados por personajes vinculados al Condado Portucalense y posteriormente al naciente reino de Portugal presenten muchos más elementos regionales propiamente

52. Sobre Ermelo, Sandra Conceição Silva Nogueira (2010): O mosteiro de Ermelo em Arcos de Valdevez. Um contributo para sua história, Dissertação de Mestrado em Arqueologia. Oporto: Universidade de Porto. Y Margarita Vázquez Corbal (2015): El arte románico en la antigua diócesis de Tui, tesis doctoral (pp. 93-95). Santiago de Compostela: Universidad de Santiago de Compostela.

53. Tendencias que ya aparecen identificadas por Carlos Alberto Ferreira de Almeida (1971): «Primeiras impressões sobre a arquitectura românica portuguesa», en Revista da Facultade de Letras, História (n. ${ }^{\circ}$ 2), pp. 65-116. Y para un análisis pormenorizado de la segunda tendência, véase la interpretación de los ejemplos del área del río Lima hecha por Lúcia Rosas (1987): A escultura românica das igrejas da margem esquerda do Minho, tesis doctoral. Oporto: Universidade de Porto. 


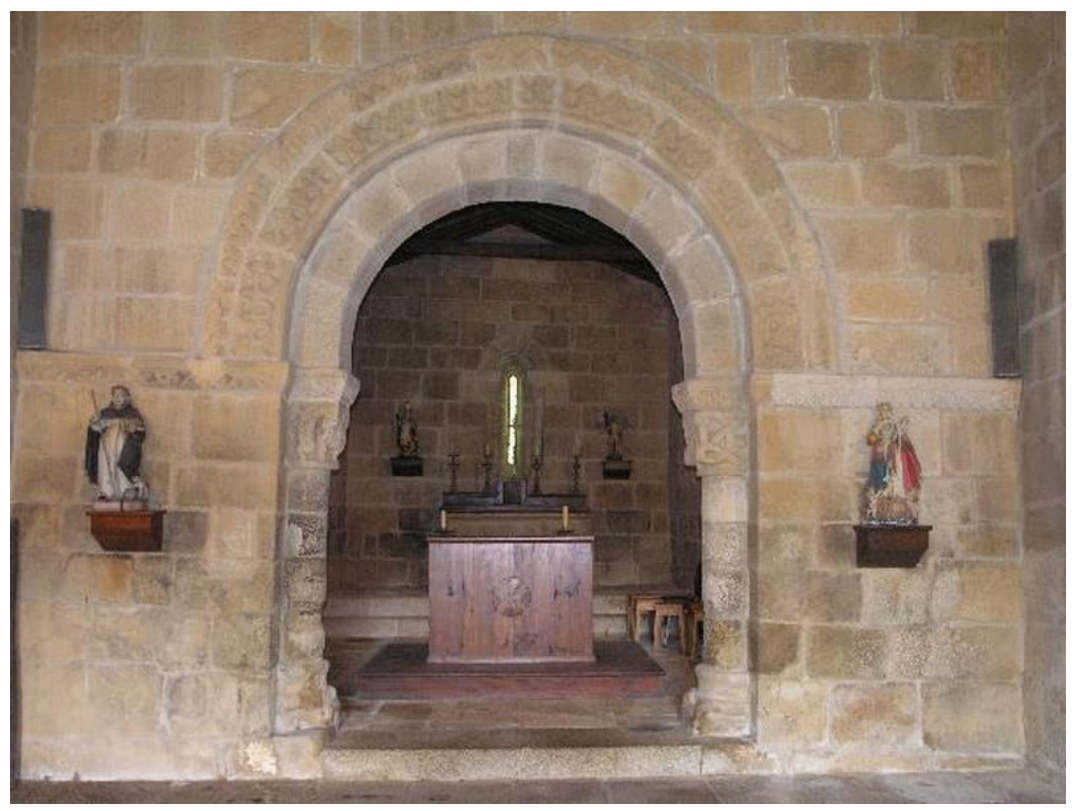

Fig. 20. Detalle de la decoración típica bracarense en la arquivolta de la portada occidental de la Iglesia de São Cláudio de Nogueira (Viana do Castelo, Portugal)

portugueses o bracarenses, como es el caso de las arquivoltas con motivos vegetales lanceolados unidos por círculos (fig. 20). Otra influencia en ellos vendrá del arte cisterciense, ${ }^{54}$ en un afán por alejarse de la influencia artística de Galicia, y por ende de León.

\section{Conclusiones}

La antigua diócesis de Tui y su arte románico suponen un interesante ejemplo de las relaciones entre monarquía, religión y poder en la Edad Media, puesto que se trata de un territorio singular, fronterizo, y es un escenario privilegiado de luchas internas y externas que implican al poder religioso y al poder real.

El arte románico en este territorio, independientemente de su valor artístico y de sus peculiaridades estilísticas, supone una valiosa maniobra de propaganda política y de reafirmación de la identidad, como atestiguan las fuentes documentales que reflejan un abundante número de donaciones y nuevas fun-

54. Sobre el Císter en Galicia, José Carlos Valle Pérez (1982): Arquitectura Cisterciense en Galicia. La Coruña: Fundación Pedro Barrié de la Maza. Y para Galicia y Portugal, Jorge Rodrigues y José CARLos VAlle Pérez (1998): Arte del Císter en Galicia y Portugal. La Coruña: Fundación Barrié de la Maza. 
daciones tanto reales como de personajes pertenecientes a la nobleza fronteriza, así como la repetición de modelos que denotan la influencia tudense o bracarense en estrecha relación con el origen de los donantes o fundadores.

Actualmente conservamos menos de un centenar de ejemplos de obras románicas entre el territorio gallego y el portugués, pero la documentación nos indica que fueron muchas más; lo cual pone de manifiesto que, si los siglos XI y XII fueron épocas de alta conflictividad política, también lo fueron de alta productividad artística, que continuó durante siglos posteriores con obras de resistencia o inercia.

\section{Bibliografía}

Aguiar, A. (2001): «Afonso Henriques e a fronteira noroeste: contornos de uma estratégia», en A construção medieval do território. Lisboa: Livros Horizonte.

ANDRAde, J. M. (1997): «Fuentes Documentales para el estudio del rey García de Galicia», en Minius (n. ${ }^{\circ}$ ), pp.41-50.

Ávila, F. (1995): Historia Civil y eclesiástica de la Catedral de Tuy y de su obispado. Santiago de Compostela: Consello da Cultura Galega.

Azevedo, Rui de (1958): Documentos Medievais Portugueses (vol. I). Lisboa: Academia Portuguesa da História.

- (1979): Documentos de D. Sancho I (1174-1211). Coimbra.

Bango, I. G. (1979): Arquitectura románica en Pontevedra. Fundación Pedro Barrié de la Maza.

BAquero, H. (1986): «Vías portuguesas de peregrinação a Santiago de Compostela na Idade Média», en Revista da Facultade de Letras da Universidade de Porto, História, n. ${ }^{\circ}$ 3, pp. 77-89.

BARbosa, J. (1727): Catálogo cronológico, histórico, genealógico e crítico das rainhas de Portugal e seus filhos. Lisboa.

Bruel, B. (1876-1903): Récueil des chartes de l'abbaye de Cluny. París: Imprimerie Nationale.

Cendón, M.: «El arte medieval en Tui: la catedral como foco receptor y difusor del románico y del gótico», en Marta Cendón Fernández, Silvia González Soutelo (2006): Tui: Pasado, presente y futuro. Pontevedra: Deputación de Pontevedra, pp. 121-155.

- (1993): «Hipótesis sobre la planta medieval de la Catedral de Tui», en Museo de Pontevedra, 47 (1993), pp. 101-122.

- (1994): «Las etapas constructivas de la catedral medieval de Tuy», en Tui. Museo e Arquivo Histórico Diocesano, VII, pp. 197-212.

- (2000): La catedral de Tui en época medieval. Pontevedra: Fundación Cultural Rutas del Románico.

— (2003): «El claustro de la catedral de Tui», en Memoria Artis. Santiago de Compostela: Xunta de Galicia, pp. 53-70.

Fernández, J. A. (1991): Colección Diplomática del Monasterio de Sahagún 857-1300. León.

Fernández, M. (2004): Toronium. Aproximación a la historia de una tierra medieval. Santiago de Compostela: Instituto Padre Sarmiento de Estudios Gallegos - CSIC.

Ferreira, C. A. (1971): «Primeiras impressões sobre a arquitectura românica portuguesa», en Revista da Facultade de Letras, História (n. ${ }^{\circ}$ 2), pp. 65-116.

- (1998): «A igreja românica de Bravães», en Avelino Jesús DA Costa: Subsídios para a história da Terra de Nóbrega e do Concelho de Ponte da Barca (vol. I). Ponte da Barca, pp. 11-26.

Flórez, E. (1967): España Sagrada (tomo XXII). Madrid.

Galindo, P. (1923): Tuy en la Baja Edad Media, siglos XII-XV. Madrid: CSIC.

García, M. R. (1962): «El diploma de restauración de la sede de Tui por la infanta Urraca», en Cuadernos de Estudios Gallegos (tomo 17, n. ${ }^{\circ}$ 52), pp. 265-292. 
GonzÁlez, J. I. (2011): O Mosteiro de San Salvador de Budiño e a terra de Toroño. Vigo: Instituto de Estudios Vigueses.

Iglesias, E. (2009): El antiguo obispado de Tui en Portugal. Noia: Toxosoutos.

- (2014): «Los capiteles románicos de la Catedral de Tui», en XXXII Ruta del Románico Internacional. Pontevedra, pp.122-124.

LóPEZ, F.: «La cristalización de Tui como espacio del poder señorial entre 1095-1157», en MARta Cendón Fernández, Silvia González Soutelo (2006): Tui: Pasado, presente y futuro. Pontevedra: Deputación de Pontevedra, pp. 57-95.

MANso, C. (2012): «Reflexiones sobre la catedral románica y gótica de Santa María de Tui», en Abrente (n. $\left.{ }^{\circ} 44\right)$, pp. 75-126.

Martínez, J. (2003): «As parroquias de Tui. Síntese Histórica», en Pontevedra. Revista de Estudos Provinciais (n. $\left.{ }^{\circ} 19\right)$, pp. 11-58.

Mattoso, J. (1995): Identificação de um país. Ensaio sobre as origens de Portugal (1096-1325), (vol. I). Lisboa: Estampa.

Portela, E. (1976): La región del obispado de Tui en los siglos XI-XV. Una sociedad en la expansión y en la crisis. Santiago de Compostela: Centro de Estudios Xacobeos - CSIC.

Recuero, M.; García, M. Â.; Romero, P. (1998): Documentos Medievales del Reino de Galicia: Alfonso VII (1116-1157). La Coruña: Xunta de Galicia.

- (2002): Documentos Medievales del Reino de Galicia: Doña Urraca (1095-1126). La Coruña: Xunta de Galicia.

Rodrigues, J.: «A imagem do poder no românico português», en MARISA Costa. (2001): Propaganda e Poder. Congresso Peninsular de História da Arte, Colibrí. Lisboa, pp. 47-56.

Rodrigues, J.; Valle, J. C. (1998): Arte del Císter en Galicia y Portugal. La Coruña: Fundación Barrié de la Maza.

- (2001): El arte românico en Galicia y Portugal. La Coruña: Fundación Pedro Barrié de la Maza.

Romero, P. (2004): «Valor de la documentación real portuguesa para la historia de Galicia en la Edad Media», en Cuadernos de Estudios Gallegos (tomo LI, fasc. 117), pp. 219-237.

- (2006): «Un observatorio privilegiado de las relaciones entre Castilla y Portugal: Tuy en la Edad Media», en Estudos em Homenagem ao Professor Doutor José Marques. Oporto: Facultade de Letras da Universidade do Porto, pp. 247-259.

Rosas, L. (1987): A escultura românica das igrejas da margem esquerda do Minho, tesis doctoral. Oporto: Universidade de Porto.

SÁNCHEZ, J. C. (2014): «Organización eclesiástica y social en la Galicia tardoantigua. Una perspectiva geográfico-arqueológica del parroquial suevo», en Hispania Sacra (n. ${ }^{\circ} 134$ ), pp. 439480.

SANDOval, P. (1973): Antigüedad de la ciudad y iglesia catedral de Tuy. El Albir.

Santa María, N. De (1668): Chronica da Ordem dos Cônegos Regrantes do Patriarcha S. Agostinho. Lisboa.

Silva, S. (2010): O mosteiro de Ermelo em Arcos de Valdevez. Um contributo para sua história. Oporto: Universidade de Porto, dissertação de Mestrado em Arqueologia.

VAlle, J. C. (1982): Arquitectura Cisterciense en Galicia. La Coruña: Fundación Pedro Barrié de la Maza.

- (2012): «Notas sobre la arquitectura románica de la provincia de Pontevedra», en García Guinea, Miguel Ángel y Pérez GonzÁlez, José María: Enciclopedia del Románico en Galicia. Aguilar de Campóo, pp. 41-70.

VÁzquez, M. (2003): «La iglesia de Santa Eulalia de Donas: un ejemplo de las relaciones artísticas entre el Baixo Miño español y portugués», en XXIV Ruta Cicloturística del Románico Internacional, 2003, pp. 150-155.

- (2008): «La iglesia y el antiguo monasterio de Vila Nova de Muía (Ponte da Barca, Portugal)», en XXVI Ruta Cicloturística del Románico Internacional, pp. 213-215.

- (2015): El arte románico en la antigua diócesis de Tui, tesis doctoral. Santiago de Compostela: Universidade de Santiago de Compostela. 
VILA, S. (2001): Tui e Valença nos séculos XI a XV: os acontecementos históricos, sociais, artísticos e econômicos. Tui: Asociación de Amigos da Catedral de Tui.

- (2009): A cidade de Tui durante a Baixa Idade Media. Noia: Toxosoutos, Noia.

Yzquierdo, R. (1989): «Motivos ornamentales de la Catedral de Tuy», en Tui. Museo y Archivo Histórico Diocesano, V, pp. 87-113.

- (1998): «Reflexiones sobre El románico de Galicia y Portugal», en LeIRA LópEZ, José. (2001): O Camiño Portugués: III Aulas no Camiño: un estudio multidisciplinar da realidade galega que atravesan os camiños de Santiago. Badajoz: Diputación de Badajoz, pp. 43-76. 